\title{
Advances in the Detection Technologies and Clinical Applications of Circulating Tumor DNA in Metastatic Breast Cancer
}

This article was published in the following Dove Press journal: Cancer Management and Research

\section{Hao Liao (D) \\ Huiping Li $\mathbb{D}$}

Key Laboratory of Carcinogenesis and Translational Research (Ministry of Education/Beijing), Department of Breast Oncology, Peking University Cancer Hospital and Institute, Beijing I00I42, People's Republic of China
Correspondence: Huiping Li Email huipingli2012@hotmail.com

\begin{abstract}
Breast cancer (BC) represents the most commonly diagnosed cancer among females worldwide. Although targeted therapy has greatly improved the efficacy of treating $\mathrm{BC}$, a large proportion of $\mathrm{BC}$ patients eventually develop recurrence or metastasis. Traditional invasive tumor tissue biopsy is short of comprehensiveness in tumor assessment due to heterogeneity. Liquid biopsy, an attractive non-invasive approach mainly including circulating tumor cell and circulating tumor DNA (ctDNA), has been widely utilized in a variety of cancers with the advances of sequencing technologies in recent years. The ctDNA that is found circulating in body fluids refers to DNA released from tumor cells and has shown clinical utility in metastatic breast cancer (MBC). With the results of genomic variants detection, ctDNA could be used to predict clinical outcomes, monitor disease progression, and guide treatment for patients with MBC. Moreover, the drug resistance problem may be addressed by ctDNA detection. In this review, we summarized the technological developments and clinical applications of ctDNA in MBC.
\end{abstract}

Keywords: circulating tumor DNA, metastatic breast cancer, genomic variants, drug resistance

\section{Introduction}

Breast cancer $(\mathrm{BC})$ represents the most commonly diagnosed cancer and the leading cause of cancer death among females worldwide. ${ }^{1}$ In China, 272.4 thousand women were newly diagnosed as $\mathrm{BC}$ each year, bringing heavy medical and financial burden to the whole society. ${ }^{2}$ The 2011 St. Gallen conference categorized BC into four subtypes based on the molecular landscape of the tumor, including luminal A, luminal B, human epidermal growth factor receptor-positive (HER2+), and triple-negative (ductal) disease. ${ }^{3}$ This surrogate classification for BC subtypes has been shown to successfully predict tumor presenting features, nodal involvement, recurrence patterns, and disease-free survival. ${ }^{4}$ Even though the 5-year mortality rate of $\mathrm{BC}$ has dropped by $34 \%$ since 1990, a number of patients eventually developed resistance to the therapy. ${ }^{5}$ For instance, the drug resistance rate of estrogen receptor-positive $(\mathrm{ER}+)$ /progesterone receptor-positive $\mathrm{BC}$ patients could reach $70 \%{ }^{6}$ Meanwhile, the treatment of advanced $\mathrm{BC}(\mathrm{ABC})$ remains a challenge due to the common drug resistance.

Tumor tissue biopsy is the gold standard specimen for tumor genotyping. However, tumor tissue biopsy is invasive, painful, and potentially risky, and performing biopsy in some tumor sites may not be convenient. ${ }^{7}$ Moreover, in 
metastatic settings it may be short of comprehensiveness due to tumor heterogeneity. ${ }^{8}$ Therefore, alternative lessinvasive detection methods are desperately required to capture the entire genetic map of the tumor and consequently improve the current treatment options. Liquid biopsy is an attractive non-invasive approach that utilizes readily available body fluids to provide a real-time comprehensive assessment of the tumor, through the analysis of genomic variants in circulating tumor DNA (ctDNA) and circulating tumor cell (CTC). ${ }^{9}$ In cancer patients, ctDNA is a small proportion of circulating cell-free DNA (cfDNA) in the bloodstream, which was first described by Mandel et al in $1948 .{ }^{10}$ With the rapid developments of sequencing technologies in recent years, the clinical applications of ctDNA in various tumors such as lung cancer, $\mathrm{BC}$, and gastric cancer have been extensively explored. ${ }^{9,11,12}$ For BC, ctDNA was shown to provide supplementary information for tumor tissue biopsy in terms of prognosis assessment, drug resistance test, and individualized treatment. ${ }^{13}$ Importantly, additional mutations detected by ctDNA could reflect the utility of liquid biopsy to capture heterogeneity of metastatic sites in ABC. ${ }^{14}$

To offer an update of current literature, this review will discuss the recent developments of ctDNA in metastatic $\mathrm{BC}(\mathrm{MBC})$ from these aspects: main detection technologies, concordance between ctDNA and tumor tissue biopsy, pre-analytical factors, tumor burden, genomic variants, specific gene mutations, drug resistance, and tumor heterogeneity and sub-clone.

\section{Main Detection Technologies for ctDNA in MBC}

It has been demonstrated that cfDNA can be released from apoptosis, necrosis, and macrophage phagocytosis of the cells, whereas the concentration of cfDNA in the bloodstream of healthy individuals is low (approximately $10 \mathrm{ng}$ / $\mathrm{mL}){ }^{15,16}$ The concentration of cfDNA can be increased by certain events like exercise, cancer, and autoimmune disease. ${ }^{17-19}$ In patients with $\mathrm{BC}$, the concentration of cfDNA may increase to $0.5,235,422$, and $1280 \mathrm{ng} / \mathrm{mL}$ classified by tumor stage I, II, III, and IV, respectively. ${ }^{20}$ However, the concentration of ctDNA or the concentration ratio of ctDNA: cfDNA can be very low given that the majority of cfDNA consists of background germline DNA. $^{21}$ Therefore, highly sensitive approaches capable of detecting the genomic profile of limited available amounts of ctDNA are demanded. So far, diverse detection methods mainly based on Polymerase Chain Reaction (PCR) and Next-Generation Sequencing (NGS) have been applied, while each has its own strength and weakness. $^{22}$

\section{PCR-Based Technologies}

The development of traditional simple PCR has shown some limitations in liquid biopsy such as its low detection sensitivity. ${ }^{23}$ Currently, digital PCR (dPCR) is frequently used for the detection of ctDNA because of its high sensitivity and ease of use. Two common dPCR methods, the droplet digital PCR (ddPCR) and BEAMing [beads, emulsification, amplification, and magnetics] assay, can accurately detect point mutations present at frequencies $\leq$ $0.1 \%$, nevertheless restricted to the analysis of a small number of genomic loci and the need of "a priori" knowledge of the investigated genomic aberrations. ${ }^{24}$ A workflow by means of uniplex or multiplex preamplification combined with dPCR was successfully used to investigate the estrogen receptor 1 (ESR1) mutation status of the samples of MBC patients who progressed on endocrine treatment. ${ }^{25}$ The combination of allelespecific, asymmetric rapid PCR and melting analysis assay was used to detect the phosphoinositide 3-kinase catalytic subunit alpha (PIK3CA) hotspot mutations (E545K, H1047R) and showed a high concordance $(81.1 \%, P=0.001)$ with ddPCR. ${ }^{26}$ Gyanchandani et al utilized a novel whole-genome amplification of cfDNA via rolling-circle amplification before ddPCR and provided physiological evidence that ctDNA was accessible by fingerstick and sustained presence/absence of mutation detection after whole-genome amplification. ${ }^{27}$

\section{NGS-Based Technologies}

NGS, compared with PCR, can interrogate larger regions such as gene panels without prior knowledge of mutations. ${ }^{28}$ The main methods of NGS consist of targeted sequencing, whole-exome sequencing, and whole-genome sequencing. ${ }^{8}$ Li et al performed targeted deep sequencing on 17 blood samples from 17 Chinese MBC patients and identified 60 somatic mutations in the blood samples of all patients. ${ }^{7}$ MammaSeq, a breast cancer-specific NGS panel, was shown to detect 43 protein-coding mutations in $14 \mathrm{ctDNA}$ samples from 7 patients with $\mathrm{ABC}$, targeting 79 genes and 1369 mutations. ${ }^{29}$ Despite of the comprehensive sequencing ability, the error rate of NGS complicates the calling of mutations with variant allele frequencies $(\mathrm{VAFs})<5 \%{ }^{28}$ 
Error correction through random molecular barcodes has been incorporated into NGS ctDNA assays to reduce this error rate, enabling mutation calling with VAFs $<0.1 \%{ }^{30}$ Masunaga et al analyzed the cfDNA samples from $34 \mathrm{MBC}$ patients and revealed a higher sensitivity $(0.1 \%)$ of the molecular barcodes-NGS than NGS without barcode (1\%) by reducing background errors. ${ }^{31}$ Nevertheless, increasing proportions of false positives and negatives have been reported at low mutant allele frequencies, which brings the issue of detection reliability. ${ }^{32}$ Importantly, reproducibility is one of the main caveats of high throughput technologies. The study by Stetson et al suggested that most NGS assay discordance is a result of technical variations. ${ }^{33}$ Gerratana et al confirmed the detection performance of a novel NGS platform, PredicinePLUS ${ }^{\mathrm{TM}}$, when compared with Guardant $360^{\mathrm{TM}}$ and that different NGS platforms could be potentially compared provided that certain sample management and analytical requirements are met. ${ }^{32}$

\section{Hybrid Techniques}

Hybrid techniques such as the combination of PCR and NGS allow to circumvent both the sensitivity limits of NGS (1-2\%) and the inherent need for "a priori" knowledge of the target of PCR. ${ }^{22}$ Studies using hybrid techniques such as synchronous coefficient of drag alteration, tagged-amplicon deep sequencing, and safe sequencing system have been summarized in a previous review. ${ }^{9}$ Recently, Keup et al analyzed 17 genes in the cfDNA of 44 MBC patients by a targeted PCR-based NGS approach. This method constructed a library using a customized targeted DNA panel with integrated unique molecular indices before sequencing. The comprehensive analysis of cfDNA variants not only confirmed the benefit of unique molecular indices in the variant verification, but also identified new promising variants with clinical relevance. ${ }^{34}$

\section{The Concordance Between ctDNA and Tumor Tissue Biopsy}

The ctDNA cannot be used to replace the need for metastatic tissue biopsy of patients until it is proven to represent the genomic information detected in solid tissue. ${ }^{35}$ A number of studies have investigated the difference between ctDNA and tumor tissue biopsy in $\mathrm{MBC}$ and some of them have revealed high concordances (77 89\%). ${ }^{36-40}$ The remarkable concordance suggests that ctDNA assays can be confidently used to molecularly stratify patients for prognostic and predictive purposes. Furthermore, compared to tumor tissue biopsy, ctDNA may have the superiority of obtaining more comprehensive mutation information. ${ }^{41}$ For example, Maxwell et al found that the proportion of genomic alteration in MBC patients was lower in tumor than in blood $(69 \%$ vs $91 \% ; P=0.06){ }^{42}$ Even so, several studies reported significant differences between the genomic results of tumor tissue biopsy and cfDNA in MBC patients. ${ }^{43-46}$ Diverse analysis tools, temporal spacing between ctDNA analysis and tumor biopsy, and tumor heterogeneity due to the substantial selection pressure from therapies perhaps contribute to this inconsistency. ${ }^{43,46,47}$

\section{Pre-Analytical Factors}

The quality of ctDNA analysis was affected by a lot of pre-analytical factors. ${ }^{9}$ Hakan et al reported a significant increase in isolation efficiency with very fresh blood samples of at least 15 milliliters which were processed in minutes. $^{48}$ Risberg et al investigated the potential preanalytical influential factors of ctDNA levels. The results revealed that using cell-stabilization tubes, storing at $4{ }^{\circ} \mathrm{C}$ after collection for a short period, and performing the centrifugation in different types of centrifuges greatly improved the feasibility of collecting high-quality specimens. $^{49}$ What's more, higher frequencies of ESR1 and PIK3CA mutations in the plasma than in the serum were revealed, indicating that plasma samples might be the preferred source of cfDNA. ${ }^{50-52}$ Possible influential factors in each step of the ctDNA detection from sample collection to sequencing are shown in Figure 1.

\section{Assessing Tumor Burden According to the Quantity and Quality of ctDNA/cfDNA}

Tumor burden provides key information about objective response and disease progression. ${ }^{53} \mathrm{MBC}$ patients with high panel-specific mutational load had a significantly shorter time to progression than those with a low mutational load $(P=0.0112){ }^{42}$ The molecular tumor burden index, a measure of the percentage of ctDNA in samples, was positively correlated with tumor size as evaluated by computed tomography $(P<0.0001)$ and detected disease progression $8-16$ weeks earlier. ${ }^{54}$

\section{The ctDNA Concentration}

Dynamic changes in ctDNA levels closely reflect changes in tumor burden and increases in ctDNA levels may predict the progressive disease (PD) several months before 


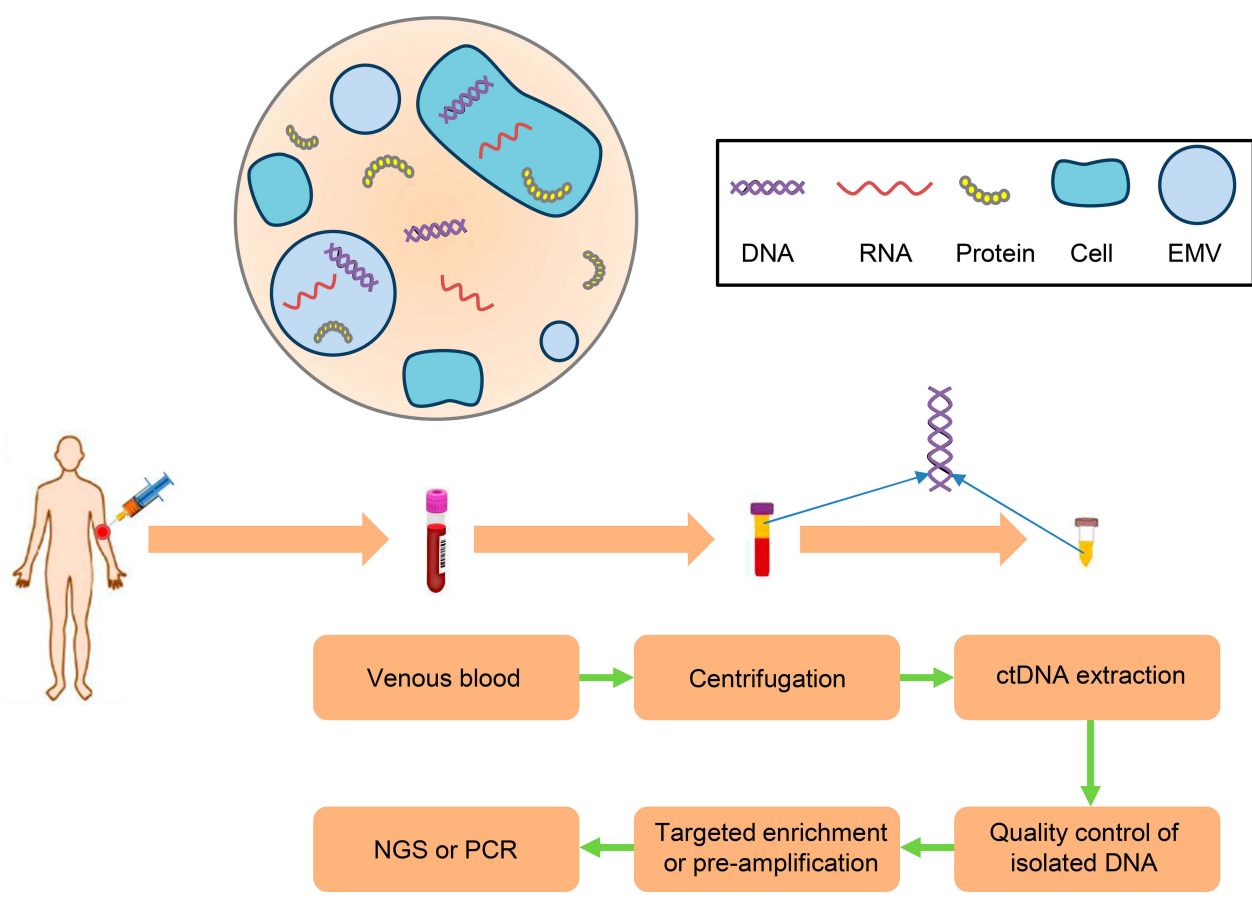

Figure I The whole process of ctDNA analysis and possible influencing factors.

Notes: The concentration of ctDNA and mutation frequency are significantly higher in $\mathrm{ABC}$ than early $\mathrm{BC}$. Using cell-stabilization tubes, storing at $4^{\circ} \mathrm{C}$ after collection for a short period, and performing the centrifugation in different types of centrifuges greatly improved the feasibility of collecting high-quality specimens. Plasma samples may be the preferred source of ctDNA than serum. The type of detection technology also affects the results of ctDNA analysis. EMV, extracellular micro vesicle; ctDNA, circulating tumor DNA; ABC, advanced breast cancer; NGS, next-generation sequencing; PCR, polymerase chain reaction.

the standard imaging. ${ }^{55}$ In recent years, several methods were used to determine the ctDNA concentration in $\mathrm{MBC}$ and investigate its relationship with clinical outcomes. Cheng et al evaluated the ctDNA concentration of MBC patients by measuring the short and long fragments of two repetitive DNA elements, ALU and LINE1, and found that ctDNA concentration could serve as an independent prognostic marker. ${ }^{56} \mathrm{Li}$ et al used the VAF of mutations from the major mutated clones to access the ctDNA levels of MBC patients. The results showed that a higher ctDNA level in plasma was associated with a shorter progressionfree survival (PFS). ${ }^{7}$

\section{The Cutoff of ctDNA Concentration}

A number of studies have demonstrated the prognostic value of a CTC enumeration $>5$ at baseline and followup in patients with $\mathrm{MBC} .^{55,57,58}$ Recently, Cristofanilli et al used a CTC threshold of 5 cells per $7.5 \mathrm{~mL}$ for the stratification of $2346 \mathrm{MBC}$ patients in a retrospective and pooled analysis of individual patient data from 18 cohorts and confirmed the identification of two subgroups of MBC (Stage $\mathrm{IV}_{\text {indolent }}$ and Stage $\mathrm{IV}_{\text {aggressive }}$ ), independent of clinical and molecular variables. ${ }^{59}$ Nevertheless, a cutoff of ctDNA concentration that correlates with a worse prognosis has not been identified yet. A recent retrospective study revealed a statistically significant difference in PFS and overall survival (OS) for baseline \%ctDNA (the maximum mutant allele fraction in each sample) $<0.5 \mathrm{vs}$. $\geq 0.5(P=0.003$ and $P=0.012) .{ }^{55}$ Stover et al presented the genomic characterization of a large metastatic triplenegative BC (MTNBC) cohort. A cfDNA tumor fraction threshold of $\geq 10 \%$ was associated with significantly worse metastatic survival. ${ }^{60}$ In one study by Shatsky et al, $\mathrm{ABC}$ patients with at least one alteration with $5 \%$ ctDNA had poorer median OS (6.7 months) vs. patients with less than $5 \%$ ctDNA (17.9 months $)(P=0.01) .{ }^{43}$

\section{The DNA Integrity}

The cfDNA concentration directly reflects the quantity of cfDNA, while the cfDNA integrity (cfDI) represents the quality of cfDNA, which has been investigated as a diagnostic or prognostic marker in multiple cancers. ${ }^{61-63}$ In general, cfDI is calculated as a ratio of longer DNA to shorter DNA for ALU repeats (247 and 115 bp). Plasma ALU-247, ALU-115, and DNA integrity may be proven to have clinical utility in $\mathrm{BC}$ diagnosis. ${ }^{64}$ In metastatic settings, Cheng et al showed a significantly increased cfDI $(P=1.21 \mathrm{E}-7$ for ALU and $P=1.87 \mathrm{E}-3$ for LINE1 $)$ in both 
repetitive DNA elements after one cycle of therapy. In addition, the multiple cox regression model indicated an independent prognostic role of cfDI. ${ }^{56}$

\section{Detecting Genomic Variants}

Besides the ctDNA concentration, the mutation frequency of ctDNA in $\mathrm{ABC}$ is significantly higher than that in early $\mathrm{BC} .^{20,23}$ Analyzing the genomic variants including somatic mutations, somatic copy number alterations (SCNAs), and DNA methylation (DNAme) may have important prognostic significance. ${ }^{65}$

\section{Somatic Mutations}

Somatic mutations identified in ctDNA are widely representative of the tumor genome as they can provide the spectrum of mutations not limited to a single region of the tumor. ${ }^{66}$ In recent years, several studies identified the somatic mutation profiles of $\mathrm{ABC} .^{40,67-69}$ Chung et al sequenced 62 genes in ctDNA from patients with ER+ $\mathrm{MBC}$ and found that the most frequently altered genes were TP53 (38\%), ESR1 (31\%), and PIK3CA (31\%). ${ }^{40}$ Ding et al identified HER2 mutations in both the tyrosine kinase $(n=14)$ and extracellular $(n=4)$ domains in MBC patients. ${ }^{67}$ In a retrospective study by $\mathrm{Yi}$ et al, authors determined the frequency and spectrum of common cancer-related gene mutations in ctDNA among different ABC subtypes. 96.0\% (96/100) female ABC patients had somatic genomic alterations including copy number variants (CNVs) and point mutations and different subtypes of $\mathrm{ABC}$ had distinct features in terms of genetic alterations. ${ }^{68}$ In one study by Zill et al, the somatic mutation landscape of 70 cancer genes from cfDNA deep sequencing analysis of 21,807 patients with advanced cancers was depicted. The results revealed the most commonly amplified genes (MYC and FGFR1) and the most common resistance alterations (ESR1 L536/Y537/D538) in $\mathrm{ABC}{ }^{69}$

\section{Somatic Copy Number Alterations}

A study by Stover et al presented the largest genomic characterization of MTNBC to date. They found that certain SCNAs were more frequent in MTNBC patients relative to primary TNBC including copy number gains in drivers NOTCH2, AKT2, and AKT3 ${ }^{60}$ Theoretically, all HER2+ patients should show a copy number gain of erbb2 receptor tyrosine kinase 2 (ERBB2). However, in a study by Yi et al, only $8.8 \%$ patients in the HER $2+$ group showed an ERBB2 copy number gain. The reason might be that the ctDNA assay was not sufficiently sensitive to accurately detect CNVs. ${ }^{68}$ This viewpoint was supported by a recent meta-analysis of Yang et al The pooled results showed that single nucleotide variants detection through cfDNA from MBC patients had higher sensitivity $(0.78[0.71-0.84])$ and specificity $(0.92$ [0.870.95]), when compared to tissue DNA detection. However, the cfDNA-based detection of CNV was shown to have no diagnostic value due to the low sensitivity $(0.42$ [0.24$0.62]$ ) in the cases of $\mathrm{CNV}^{70}$

\section{DNA Methylation}

DNAme has been considered as a hallmark of cancer over the last decade. ${ }^{71}$ DNAme means the covalent addition of a methyl group to cytosine within the context of $\mathrm{CpG}$ dinucleotide and is chemically and biologically stable. ${ }^{72,73} \mathrm{Le}$ et al examined the promoter methylation status of a panel of markers in a range of $\mathrm{BC}$ cell lines spanning the epithelialmesenchymal spectrum with methylation-sensitive highresolution melting. A distinction in profiling DNA methylation was revealed between epithelial and mesenchymal phenotypes. ${ }^{74}$ This study provided important insight into selecting an optimal panel of methylation markers to assess minimal residual disease, which is a major determinant of the initiation of metastatic tumors. ${ }^{75}$ Panagopoulou et al assessed the methylation status of a panel of cancer-related genes in BC. The methylation of WNT5A was statistically significantly correlated to greater tumor size and poorer prognosis characteristics and in advanced stage disease with shorter OS. In the metastatic group, SOX17 methylation was significantly correlated to shorter PFS and OS. ${ }^{76}$ These studies highlighted that DNA methylation should be further evaluated as a potential liquid biopsy-based biomarker in metastatic settings.

\section{The Significance of Detecting Specific Gene Mutations}

The identification of specific point mutations such as PIK3CA and ESR1 in BC may provide key information for the selection of treatment regimens. ${ }^{77}$ In MBC, the mutation profile of specific genes could be utilized to predict clinical outcomes. Importantly, crucial adjustments of treatment regimens could be made corresponding to the changes of genetic information. ${ }^{78}$ The detection sites and clinical relevance of detecting specific gene mutations in the ctDNA of $\mathrm{ABC}$ patients from studies in recent years are summarized in Table 1. 
Table I Selected Studies Detecting Specific Gene Mutations in Recent Years

\begin{tabular}{|c|c|c|c|c|c|}
\hline $\begin{array}{l}\text { Mutant } \\
\text { Gene }\end{array}$ & Detection Sites & Researcher & Study Type & $\begin{array}{l}\text { Patients } \\
\text { Classification }\end{array}$ & Clinical Relevance \\
\hline PIK3CA & $\begin{array}{l}\text { Not specific } \\
\text { R88Q, R93Q/W, KIIIE/N, } \\
\text { GII8D, E365K, C420R, E542K, } \\
\text { E545G/K, Q546K, and HI047L/ } \\
\text { R/Y } \\
\text { E542K, E545K, and HI047L/R } \\
\text { E542K, E545K, and HI047R } \\
\text { E542K, E545K, and HI047R } \\
\text { E542K, E545G/K, Q546K, } \\
\text { MI043I, and HI047 L/R/Y } \\
\text { E545K, and HI047R } \\
\text { E542K, E545K, and HI047L/R } \\
\text { E545K, and HI047R } \\
\text { E542K, E545K, and HI047R }\end{array}$ & $\begin{array}{l}\text { Takano et } \mathrm{al}^{65} \\
\text { Di Leo et } \mathrm{al}^{37} \\
\text { Li et al }{ }^{84} \\
\text { Kodahl et al }{ }^{38} \\
\text { Tzanikou et al } \\
\text { Jacot et al }\end{array}$ & $\begin{array}{l}\text { Formal-prospective } \\
\text { /retrospective study } \\
\text { Observational } \\
\text { study } \\
\text { Observational } \\
\text { study } \\
\text { Observational } \\
\text { study }\end{array}$ & $\begin{array}{l}\text { HR+HER2- } \\
A B C \\
\text { MTNBC } \\
\text { HER2+ MBC } \\
\text { HR+HER2- } \\
\text { ABC } \\
\text { ABC } \\
\text { ABC } \\
\text { MBC } \\
\text { ER+/HER2 } \\
-A B C\end{array}$ & $\begin{array}{l}\text { Predicting the efficacy of pyrotinib } \\
\text { Associated with longer PFS in patients } \\
\text { with PIK3CA mutation than patients } \\
\text { without PIK3CA mutation } \\
\text { Predicting PFS of ABC patients on } \\
\text { palbociclib and fulvestrant. } \\
\text { Revealing PIK3CA mutational status in } \\
\text { cfDNA from blood samples of } \\
\text { MTNBC } \\
\text { Exploring the predictive value of the } \\
\text { differential benefit of anti-HER2 drugs } \\
\text { PFS was in favour of buparlisib plus } \\
\text { fulvestrant versus fulvestrant alone in } \\
\text { patients with PIK3CA mutations } \\
\text { Associated with shorter median PFS } \\
\text { and worse OS } \\
\text { Changes in PIK3CA ctDNA level } \\
\text { correlated with treatment response } \\
\text { Concordance of PIK3CA hotspot } \\
\text { mutations between ctDNA and CTCs } \\
\text { Four-week persistence of cfDNA } \\
\text { PIK3CA mutation appears highly } \\
\text { correlated with PFS }\end{array}$ \\
\hline ESRI & $\begin{array}{l}\text { E380Q, D538G, S463P, L536R, } \\
\text { and Y537S/N/C } \\
\text { D538G, and Y537S/N/C } \\
\text { E380Q, D538G, Y537S/N/C, } \\
\text { V534E, L536Q/R }\end{array}$ & $\begin{array}{l}\text { Takeshita et } \mathrm{al}^{94} \\
\text { Yi et al } \\
\text { Beije et } \mathrm{al}^{93} \\
\text { Takeshita et al }{ }^{46} \\
\text { O'Leary et } \mathrm{al}^{82} \\
\text { Allouchery } \\
\text { et al }\end{array}$ & $\begin{array}{l}\text { Retrospective study } \\
\text { Retrospective study } \\
\text { Observational } \\
\text { study } \\
\text { Retrospective study }\end{array}$ & $\begin{array}{l}\mathrm{ER}+\mathrm{MBC} \\
\mathrm{ABC} \\
\mathrm{MBC} \\
\mathrm{MBC}\end{array}$ & $\begin{array}{l}\text { Prevalence of ESRI mutation in } \\
\text { Japanese MBC patients } \\
\text { Positively related to the line of } \\
\text { endocrine therapy } \\
\text { Conferring endocrine resistance } \\
\text { Independent distribution of ESR I } \\
\text { mutations between plasma and tumor } \\
\text { tissue } \\
\text { ESR I ctDNA dynamics offering } \\
\text { limited prediction of clinical outcome. } \\
\text { ESRI mutation frequency increased } \\
\text { with the development of relapse and } \\
\text { progression } \\
\text { Elevated ESR Imutation associated } \\
\text { with worse PFS }\end{array}$ \\
\hline HER2 & $\begin{array}{l}\text { Not specific } \\
\text { Not specific } \\
\text { Not specific }\end{array}$ & $\begin{array}{l}\text { Ma et al } \\
\text { Sakai et al } \\
\text { Li et al } \\
102\end{array}$ & $\begin{array}{l}\text { Single-arm phase II } \\
\text { study } \\
\text { Retrospective study } \\
\text { Phase I study }\end{array}$ & $\begin{array}{l}\text { HER2 }{ }^{\text {mut }} \text {, non- } \\
\text { amplified MBC } \\
\text { HER2+ MBC } \\
\text { HER2+ MBC }\end{array}$ & $\begin{array}{l}\text { As a screening tool to identify future } \\
\text { trial patients } \\
\text { Predicting primary resistance to } \\
\text { T-DMI } \\
\text { Multiple genetic alterations } \\
\text { significantly associated with shorter } \\
\text { PFS compared to none or one genetic } \\
\text { alteration }\end{array}$ \\
\hline
\end{tabular}

(Continued) 
Table I (Continued).

\begin{tabular}{|l|l|l|l|l|l|}
\hline $\begin{array}{l}\text { Mutant } \\
\text { Gene }\end{array}$ & Detection Sites & Researcher & Study Type & $\begin{array}{l}\text { Patients } \\
\text { Classification }\end{array}$ & Clinical Relevance \\
\hline RBI & Not specific & $\begin{array}{l}\text { Condorelli } \\
\text { et al }\end{array}$ & $\begin{array}{l}\text { Observational } \\
\text { study }\end{array}$ & HER2+ MBC & $\begin{array}{l}\text { Conferring therapeutic resistance of } \\
\text { CDK4/6 inhibitor }\end{array}$ \\
\hline BCL2 & Not specific & Lok et al ${ }^{97}$ & Phase lb study & BCL2+ MBC & $\begin{array}{l}\text { Combination therapy for patients } \\
\text { with BCL2-positive tumors }\end{array}$ \\
\hline
\end{tabular}

Notes: PIK3CA, phosphoinositide 3-kinase catalytic subunit alpha; ESRI, estrogen receptor I; HER2, human epidermal growth factor receptor 2; RBI, retinoblastoma I; $B C L 2$, B-cell lymphoma 2; MBC, metastatic breast cancer; HR, hormone receptor; ABC, advanced breast cancer; MTNBC, metastatic triple-negative breast cancer; ER, estrogen receptor; PFS, progression-free survival; OS, overall survival; CTC, circulating tumor cell; TDM-I, trastuzumab emtansine; CDK4/6, cyclin-dependent kinase 4 and $6 ;+$, positive; -, negative.

\section{PIK3CA}

PIK3CA, an oncogene encoding the p110 $\alpha$ component of the phosphoinositide 3-kinase (PI3K), represents one of the most frequent driver mutations observed in $\mathrm{BC} .{ }^{38}$ As shown in Figure 2, the four most frequent hotspot mutations of PIK3CA are located within two exons (exon 9: E545K and E542K; exon 20: H1047R and H1047L), accounting for $80-90 \%$ of all PIK3CA mutations in human malignancies. ${ }^{79,80}$ High-frequency $\quad(35 / 73$ (47.9\%)) PIK3CA hotspot mutations were present in the plasma-ctDNA of MBC patients. ${ }^{26}$ Park et al reported that more than $70 \%$ of the cfDNA samples of patients with MTNBC had PIK3CA hotspot mutations and the mutation frequency increased after the treatment. ${ }^{81}$
In recent years, a number of studies supporting the prognostic role of PIK3CA in $\mathrm{ABC}$ have been carried out. $^{36-38,45,65,82-84}$ O'Leary et al found that PIK3CA ctDNA level after 15 days' treatment strongly predicted the PFS of $\mathrm{ABC}$ patients on palbociclib and fulvestrant (hazard ratio 3.94 , log-rank $P=0.0013$ ). ${ }^{82}$ In a study by Jacot et al, a detectable circulating PIK3CA mutation after 4 weeks' hormone therapy was highly correlated with a worse $\mathrm{PFS}^{83} \mathrm{~A}$ retrospective study by $\mathrm{Li}$ et al revealed that PIK3CA p.H1047R mutation was more frequent in HER2+ disease and associated with worse OS. Moreover, this was the only mutation associated with shorter PFS on multivariate analysis in HER2+ patients who were treated with trastuzumab, suggesting
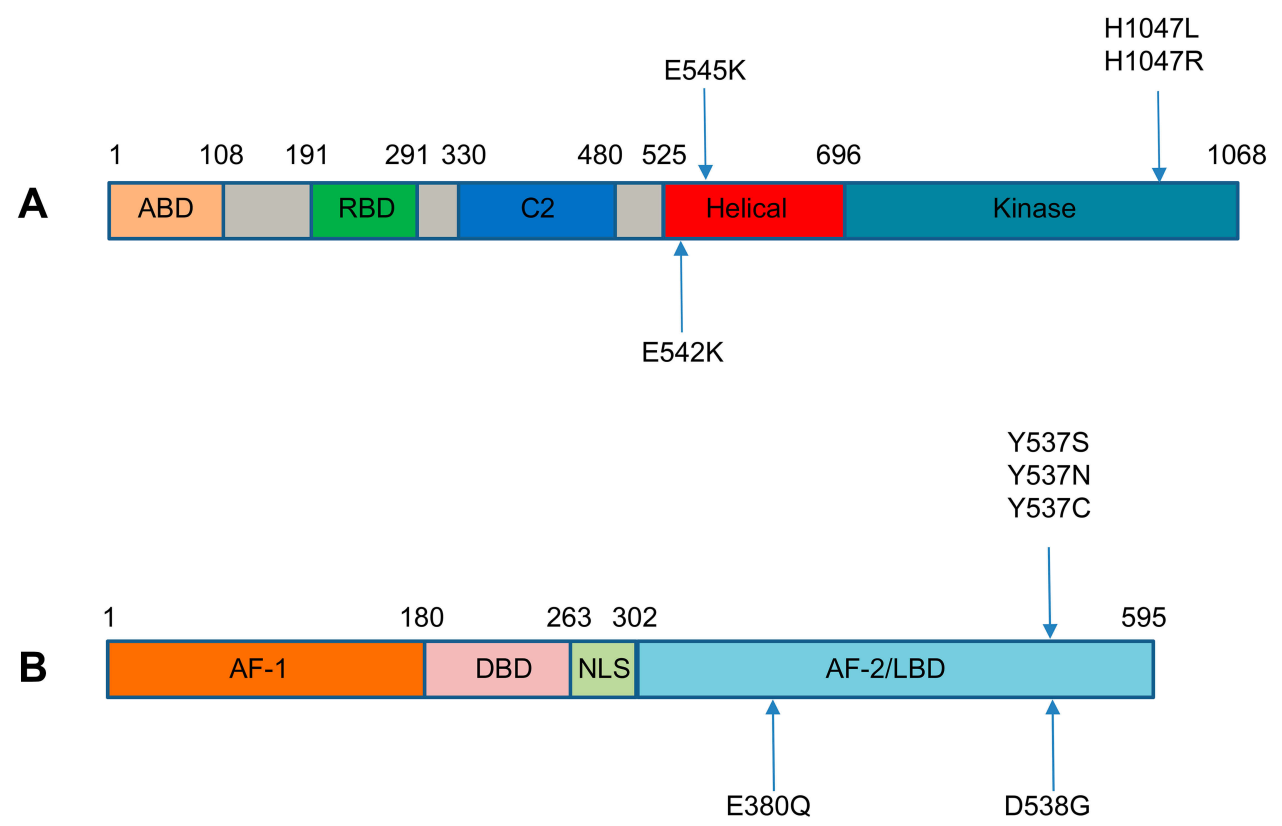

Figure 2 Major mutation sites of (A) PIK3CA and (B) ESRI.

Notes: Most of the reported mutations in PIK3CA cluster in conserved regions within the region coding for the helical and kinase domains of $\mathrm{PII} \alpha$, including E542K, E545K, HI047L, and HI047R. ESRI point mutations mainly localized in the ligand-binding domain, including 3 hotspot mutations in codons 380, 537, and 538. ABD, adaptor binding domain; RBD, ras binding domain; AF, activation function; DBD, DNA binding domain; NLS, nuclear localizing signal; LBD, ligand binding domain. 
that trastuzumab had lower activity in these patients. ${ }^{84}$ Takano et al found that in patients without PIK3CA mutations, lapatinib plus capecitabine (LX) yielded relatively longer PFS $(P=0.035)$ and $\operatorname{OS}(P=0.025)$ than trastuzumab plus capecitabine (HX), indicating that these patients might benefit from LX rather than $\mathrm{HX}^{65}$ In a Phase I study by $\mathrm{Ma}$ et al, all patients with PIK3CA or TP53 mutations were relatively insensitive to pyrotinib, whereas a significantly higher response rate was revealed in patients with wild-type PIK3CA and TP53 $(P=0.013){ }^{45}$ The BELLE-2 study was the first randomized Phase 3 clinical trial to include a prospective analysis of PFS in patients with ctDNA PIK3CA mutations. A significant difference in PFS in the buparlisib group vs. the placebo group was recorded in patients with ctDNA PIK3CA mutations, but not in patients with non-mutant ctDNA. ${ }^{36}$ On this basis, Di Leo et al demonstrated that PFS was in favour of combination therapy (buparlisib plus fulvestrant) vs. fulvestrant alone in patients with PIK3CA mutations in the BELLE-3 study. ${ }^{37}$ Overall, the ctDNA was analyzed in 1698 ABC patients of these studies and 552 (31.5\%) of them had PIK3CA mutations. Of note, 1429 of these patients had $\mathrm{HR}+\mathrm{ABC}$ and $31.1 \%$ (445/1429) had PIK3CA mutations. Available data indicates that H1047R (118/256) and E545K (94/256) are the two most frequent mutation sites in PIK3CA (Table 2). These studies suggest that PIK3CA may be a powerful target to predict the clinical outcomes and guide treatment decisions especially for HR+ or HER2+ MBC.

\section{ESR I}

The activation of ESR1 is a key feature of $70-80 \%$ BC patients in whom ER expression is detected. ${ }^{85}$ As shown in Figure 2, ESR1 point mutations mainly localized in the ligand-binding domain (LBD), including 3 hotspot mutations in codons 380, 537, and 538. Allouchery et al found

Table 2 The Distribution of PIK3CA Mutation Sites

\begin{tabular}{|l|l|l|l|l|l|}
\hline Researcher & E542K & E545K & H O47L & HIO47R & Total \\
\hline Park et al $^{81}$ & 3 & 2 & 0 & 15 & 20 \\
Takano et al $^{65}$ & 0 & 0 & 0 & 8 & 8 \\
Di Leo et al $^{37}$ & 25 & 50 & 7 & 54 & 136 \\
Kodahl et al $^{38}$ & 2 & 5 & 3 & $1 \mathrm{I}$ & $2 \mathrm{I}$ \\
Tzanikou et al $^{26}$ & 0 & 30 & 0 & 15 & 45 \\
Jacot et al $^{83}$ & 4 & 2 & 0 & 4 & 10 \\
Li et al $^{84}$ & 0 & 5 & 0 & $1 \mathrm{I}$ & 16 \\
& 34 & 94 & 10 & 118 & 256 \\
\hline
\end{tabular}

that the mutation frequency of ESR1 increased with the development of relapse and progression (5.3\% and 33\%, respectively), suggesting that detecting circulating ESR1 mutations should be focused on the metastatic setting. ${ }^{86}$ A secondary analysis of the BOLERO-2 clinical trial by Chandarlapaty et al demonstrated that each of the ESR1 mutations was associated with shorter OS. ${ }^{87}$ Paoletti et al found that patients with persistently elevated ESR1LBDm + ctDNA had worse PFS than patients who did not $(P=$ $0.0007){ }^{88}$ However, an analysis of the data from PALOMA-3 study indicated that ESR1 mutations selected by prior hormone therapy were frequently sub clonal, with ESR1 ctDNA dynamics offering limited prediction of clinical outcomes. $^{82}$

Endocrine therapy is the basis of treatment for ER+ MBC patients. However, $40 \%$ of these patients obtain no clinical benefit from first-line endocrine therapy, and virtually all of the patients in whom the tumor initially responds eventually develop resistance. ${ }^{89}$ ESR1 mutation emergence has been recently highlighted as a frequent mechanism of acquired aromatase inhibitor (AI) resistance in the metastatic setting. ${ }^{90,91}$ It was found that the mutation frequency of ESR1 was significantly higher in HR+ patients than in HR- patients, especially in the HR +/HER2- group. In addition, ESR1 mutations were positively related to the line of endocrine therapy. These results support the viewpoint that ESR1 mutations are acquired from endocrine therapy. ${ }^{68,92}$ Beije et al reported that the ESR1 mutations of cfDNA were more prevalent in the progressing cohort $(42 \%)$ than in the baseline cohort $(11 \%)(P=0.04)$, which strongly suggested a role in conferring endocrine resistance in $\mathrm{MBC} .{ }^{93}$ Takeshita et al showed that there were distinct populations of ESR1 mutations in metastatic tissue and plasma. ${ }^{94}$ Each ESR1 mutation might have different clinical significance, and it would be necessary to investigate them all. This viewpoint is consistent with Chandarlapaty et al In their analysis, the ESR1 D538G mutation group derived a large benefit from treatment with a mechanistic target of rapamycin kinase (mTOR) inhibitor, whereas the ESR1 Y537S mutation group did not. ${ }^{87}$ Altogether, the ctDNA was analyzed in $685 \mathrm{ABC}$ patients and $169(24.7 \%)$ of them had ESR1 mutations in these studies. Notably, 524 of these patients had HR+ ABC and 26.9\% (141/524) had ESR1 mutations. D538G (23/56) and Y537S (18/56) are the two most frequent mutation sites in ESR1 (Table 3). Selected by the treatment pressure, ESR1 mutations in ABC often evolve into polyclone, which may weaken its prognostic 
Table 3 The Distribution of ESRI Mutation Sites

\begin{tabular}{|l|l|l|l|l|l|l|}
\hline Researcher & E380Q & D538G & Y537S & Y537N & Y537C & Total \\
\hline Yi et al $^{68}$ & 2 & 7 & 7 & 2 & 0 & 18 \\
Beije et al $^{93}$ & 0 & 8 & 2 & 1 & 1 & 12 \\
Takeshita et al $^{46}$ & 0 & 2 & 4 & 4 & 0 & 10 \\
Paoletti et al $^{88}$ & 0 & 6 & 5 & 5 & 12 & 16 \\
& 2 & 23 & 18 & 16 & 56 \\
\hline
\end{tabular}

value. Still, detecting the mutation profile of ESR1 may assist in knowing the resistance mechanism of endocrine therapy and guiding clinical treatment (for example, the use of fulvestrant in ABC patients after AI treatment).

\section{Other Gene Mutations}

Besides ESR1 and PIK3CA, the clinical impacts of other gene mutations such as HER2, retinoblastoma 1 (RB1), and B-cell lymphoma 2 (BCL2) have been investigated in ABC. ${ }^{95-97}$ HER2 is a well-established therapeutic target in BC. ${ }^{98-100}$ HER2 gene amplification in ctDNA and ER/ PR status may predict primary resistance to T-DM1 (trastuzumab emtansine), which is an antibody-drug conjugate with high efficacy approved for the treatment of patients with HER2+ ABC. ${ }^{101}$ In a phase I study by Li et al, HER 2 bypass signaling pathway along with $\mathrm{PI} 3 \mathrm{~K} / \mathrm{AKT} / \mathrm{mTOR}$ pathway and TP53 was shown to be significantly associated with poorer PFS in patients with HER2+ MBC treated with the combination of pyrotinib and capecitabine (median, 16.8 vs. 29.9 months, $P=0.006$ ). ${ }^{102}$ Theoretically, HER2- (nonamplified) BC patients do not benefit from HER2-directed drugs. ${ }^{103}$ However, recent identification of recurrent HER2 mutations (HER2 ${ }^{\text {mut }}$ ) in a subset of HER2 gene nonamplified BC suggested an additional HER2 targeting opportunity. ${ }^{95,104-106} \mathrm{RB} 1$ is a tumor suppressor protein that is dysfunctional in several major cancers. ${ }^{107}$ Deregulation of the cyclin D1-CDK4/6-RB pathway is implicated in endocrine treatment resistance. ${ }^{108}$ Condorelli et al described the acquisition of de novo RB1 mutations in three patients with MBC treated with CDK4/6 inhibitors. None of the RB1 mutations was present in the pre-CDK4/6 specimen, highlighting that these molecular alterations likely emerged under selective pressure from the CDK4/6 inhibitor potentially conferring therapeutic resistance. ${ }^{96}$ Further research is needed to identify the frequencies of these mutations and how these mutations temporally emerge under the selective pressure of CDK4/6 treatment. BCL2, a key member of the BCL2 pro-survival family, is often expressed at high levels in poorer-prognosis luminal B tumors and in good-prognosis luminal A tumors. ${ }^{109,110}$ Lok et al demonstrated that combining venetoclax with endocrine therapy had a tolerable safety profile and elicited notable activity in ER+BCL2+ MBC. Their findings warrant further investigation of combination therapy for patients with BCL2+ tumors. ${ }^{97}$

\section{Drug Resistance}

Targeted therapies have remarkably changed the treatment of cancer over the last decade. However, almost all tumors acquire resistance to systemic treatment as a result of tumor heterogeneity and clonal evolution. ${ }^{111}$ Multiple mechanisms involved in signal transduction molecules have been demonstrated to be associated with the primary or acquired resistance in $\mathrm{ABC}$, including activation of various intracellular pathways such as the PI3K/AKT/ mTOR and CDK4/6/RB pathways. ${ }^{83,102}$

\section{Resistance to Endocrine Therapy in ER $+\mathrm{BC}$}

ESR1 mutation is not only associated with AI treatment failure in ER+ BC patients, but also confers ligand independent cell growth and relative resistance to tamoxifen and fulvestrant. ${ }^{112,113}$ Moreover, the crosstalk between PI3K and ER pathway and between PI3K/ERBB2 pathway also cause patients' resistance to endocrine therapy. ${ }^{114}$ Zhou et al evaluated the genetic response of ctDNA to chemotherapy in ER $+\mathrm{MBC}$ patients. The results showed that more patients with PD exhibited increased PIK3CA mutation frequency than non-PD patients $(56.25 \%$ vs $0 \%, P=0.002)$. Furthermore, ESR 1 and GATA3 mutations were shown to correlate with PIK3CA mutation, suggesting that the accumulation of PIK3CA, ESR1 and GATA3 mutations might significantly increase the risk of endocrine therapy resistance. ${ }^{115}$

\section{Resistance to CDK4/6 Inhibitors}

Selective CDK4/6 inhibitors have become the standard of care for ER+HER2- MBC patients. ${ }^{116}$ These agents prevent cell cycle progression from $\mathrm{G} 0 / \mathrm{G} 1$-phase to S-phase by directly blocking the activity of the cyclin D-CDK4/6 
holoenzyme, leading to the proliferation inhibition of sensitive tumor cells. ${ }^{117}$ The potent anticancer activity of CDK4/ 6 inhibitors has been demonstrated in pre-clinical and clinical studies. ${ }^{118,119}$ However, little is known about the mechanisms of resistance to these agents. Therefore, there is a pressing need to develop biomarker approaches to identify which $\mathrm{ER}+\mathrm{BC}$ patients will derive long-term benefit from CDK4/6 inhibition. O' Leary et al conducted ctDNA sequencing to 195 patients from the PALOMA-3 study. The evolution of ESR1 mutations was observed, with selection of ESR1 Y537S as the variant most likely promoting resistance to fulvestrant in the combination. ${ }^{120}$ Formisano et al identified FGFR1/2 amplification or activating mutations in 14/34 (41\%) post-progression specimens by sequencing the ctDNA in 34 patients after progression on CDK4/6 inhibitors. In addition, the presence of FGFR1 alterations in baseline plasma tumor DNA was associated with a shorter PFS in the MONALEESA-2 study, suggesting that aberrant FGFR signaling was a potential mechanism of escape from endocrine therapy plus CDK4/6 inhibitors. ${ }^{121}$

\section{Tumor Heterogeneity and Sub-Clone}

Intra-tumoral genetic heterogeneity presents a challenge to targeted therapy response, as sub-clones may have divergent response to therapy. ${ }^{82} \mathrm{~A}$ study by Ma et al provided evidence that tumor heterogeneity present in ctDNA could predict therapeutic outcome. The results indicated that patients with higher tumor heterogeneity had significantly worse PFS outcomes, with a median PFS of 30.0 weeks vs. 60.0 weeks for patients with low tumor heterogeneity $(P=0.02) .^{54}$ Sub-clonal mutations are reported most commonly in ESR1. Multiple concurrent ESR1 genomic alterations including mutation, rearrangement, and amplification were observed in $40 \%$ of ESR1-altered cases, suggesting polyclonal origin. ${ }^{40}$ Paoletti et al proposed that integrating multiple biomarkers (ctDNA ESR1LBDm, CTC enumeration, and CTC-ER status) could improve outcome prediction and endocrine treatment resistance mechanisms' identification over a single biomarker. $^{88} \mathrm{Li}$ et al explored potential predictive biomarkers of HER2+ MBC patients and found that compared to none or one genetic alteration, multiple genetic alterations in HER2 bypass signaling pathway, PI3K/AKT/mTOR pathway, and TP53 were significantly associated with poorer PFS (median, 16.8 vs 29.9 months, $P=0.006) .^{102}$

\section{Summary and Conclusions}

Compared to tumor tissue biopsy, ctDNA can noninvasively detect more comprehensive genomic information from limited amount of plasma. In recent years, great progress has been made in the detection technologies of liquid biopsy from PCR to NGS, providing strong technical support for ctDNA analysis. A lot of efforts were made to increase the sensitivity and reduce the error rate of ctDNA sequencing, leading to an improvement of the quality control of ctDNA analysis. Recent studies have revealed high concordances (77-89\%) between ctDNA and tumor tissue biopsy, which confirmed the detection capability of ctDNA and its role in replacing tumor tissue biopsy. In addition, a series of pre-analytical factors such as sample freshness, storage tube and temperature, and centrifugation speed could affect the analysis results of ctDNA and should be controlled appropriately. Tumor burden, providing key information about objective response and disease progression, could be reflected through the evaluation of ctDNA concentration and integrity. The prognostic value of specific gene mutations such as PIK3CA in MBC has been confirmed in numerous studies. Hopefully, by longitudinally monitoring the treatment response and ctDNA variants of MBC patients, the drug resistance may be addressed, however, which needs to be further validated in large-scale prospective trials. Moreover, given that the previous ctDNA tests are mainly for patients with advanced cancers, the applications of ctDNA in early-stage cancers, such as early diagnosis, relapse monitoring, and screening may be well explored. To conclude, ctDNA has promising prospects in cancer research, especially in promoting the realization of personalized medicine, and perhaps it will completely change the existing patterns of cancer treatment in the near future.

\section{Author Contributions}

All authors made substantial contributions to conception and design, acquisition of data, or analysis and interpretation of data; took part in drafting the article or revising it critically for important intellectual content; gave final approval of the version to be published; and agree to be accountable for all aspects of the work.

\section{Disclosure}

The authors declare that they have no conflict of interest. 


\section{References}

1. Bray F, Ferlay J, Soerjomataram I, Siegel RL, Torre LA, Jemal A. Global cancer statistics 2018: GLOBOCAN estimates of incidence and mortality worldwide for 36 cancers in 185 countries. $C A$ Cancer J Clin. 2018;68(6):394-424. doi:10.3322/caac.21492

2. Chen W, Zheng R, Baade PD, et al. Cancer statistics in China, 2015. CA Cancer J Clin. 2016;66(2):115-132. doi:10.3322/ caac. 21338

3. Goldhirsch A, Wood WC, Coates AS, Gelber RD, Thurlimann B, Senn HJ. Strategies for subtypes - dealing with the diversity of breast cancer: highlights of the St. Gallen international expert consensus on the primary therapy of early breast cancer 2011 Ann Oncol. 2011;22(8):1736-1747. doi:10.1093/annonc/mdr304

4. Vasconcelos I, Hussainzada A, Berger S, et al. The St. Gallen surrogate classification for breast cancer subtypes successfully predicts tumor presenting features, nodal involvement, recurrence patterns and disease free survival. Breast. 2016;29:181-185. doi:10.1016/j.breast.2016.07.016

5. DeSantis C, Ma J, Bryan L, Jemal A. Breast cancer statistics, 2013. CA Cancer J Clin. 2014;64(1):52-62. doi:10.3322/caac.21203

6. Robinson DR, Wu YM, Vats P, et al. Activating ESR1 mutations in hormone-resistant metastatic breast cancer. Nat Genet. 2013;45 (12):1446-1451. doi:10.1038/ng.2823

7. Li S, Wang X, Li Y, Lai H, Liu Y, Jin L. Non-invasive analysis of tumor mutation profiles and druggable mutations by sequencing of cell free DNA of Chinese metastatic breast cancer patients. Thorac Cancer. 2019;10(4):807-814. doi:10.1111/1759-7714.13002

8. Appierto V, Di Cosimo S, Reduzzi C, Pala V, Cappelletti V, Daidone MG. How to study and overcome tumor heterogeneity with circulating biomarkers: the breast cancer case. Semin Cancer Biol. 2017;44:106-116. doi:10.1016/j.semcancer.2017.04.007

9. Buono G, Gerratana L, Bulfoni M, et al. Circulating tumor DNA analysis in breast cancer: is it ready for prime-time? Cancer Treat Rev. 2019;73:73-83. doi:10.1016/j.ctrv.2019.01.004

10. Mandel P, Metais P. Les acides nucléiques du plasma sanguin chez l'homme (Nucleic acids in human blood plasma). C R Seances Soc Biol Fil. 1948;142(3-4):241-243.

11. Lim M, Kim CJ, Sunkara V, Kim MH, Cho YK. Liquid biopsy in lung cancer: clinical applications of circulating biomarkers (CTCs and ctDNA). Micromachines (Basel). 2018;9(3):100. doi:10.3390/ mi9030100

12. Gao Y, Zhang K, Xi H, et al. Diagnostic and prognostic value of circulating tumor DNA in gastric cancer: a meta-analysis. Oncotarget. 2017;8(4):6330-6340. doi:10.18632/oncotarget.14064

13. Zhang $\mathrm{X}$, Ju S, Wang X, Cong H. Advances in liquid biopsy using circulating tumor cells and circulating cell-free tumor DNA for detection and monitoring of breast cancer. Clin Exp Med. 2019;19 (3):271-279. doi:10.1007/s10238-019-00563-w

14. Savas P, Teo ZL, Lefevre C, et al. The subclonal architecture of metastatic breast cancer: results from a prospective communitybased rapid autopsy program "CASCADE". PLoS Med. 2016;13 (12):e1002204. doi:10.1371/journal.pmed.1002204

15. Cappelletti V, Appierto V, Tiberio P, Fina E, Callari M, Daidone MG. Circulating biomarkers for prediction of treatment response. J Natl Cancer Inst Monogr. 2015;2015(51):60-63. doi:10.1093/jncimonographs/lgv006

16. Fournie GJ, Gayral-Taminh M, Bouche JP, Conte JJ. Recovery of nanogram quantities of DNA from plasma and quantitative measurement using labeling by nick translation. Anal Biochem. 1986;158(2):250-256. doi:10.1016/0003-2697(86)90545-2

17. Kohler C, Radpour R, Barekati Z, et al. Levels of plasma circulating cell free nuclear and mitochondrial DNA as potential biomarkers for breast tumors. Mol Cancer. 2009;8(1):105. doi:10.1186/ 1476-4598-8-105
18. Tug S, Helmig S, Menke J, et al. Correlation between cell free DNA levels and medical evaluation of disease progression in systemic lupus erythematosus patients. Cell Immunol. 2014;292 (1-2):32-39. doi:10.1016/j.cellimm.2014.08.002

19. Breitbach S, Tug S, Simon P. Circulating cell-free DNA: an up-coming molecular marker in exercise physiology. Sports Med. 2012;42(7):565-586. doi:10.2165/11631380-000000000-00000

20. Tangvarasittichai $\mathrm{O}$, Jaiwang $\mathrm{W}$, Tangvarasittichai $\mathrm{S}$. The plasma DNA concentration as a potential breast cancer screening marker. Indian J Clin Biochem. 2015;30(1):55-58. doi:10.1007/s12291013-0407-z

21. Board RE, Williams VS, Knight L, et al. Isolation and extraction of circulating tumor DNA from patients with small cell lung cancer. Ann N Y Acad Sci. 2008;1137(1):98-107. doi:10.1196/annals.14 48.020

22. Diaz LA Jr., Bardelli A. Liquid biopsies: genotyping circulating tumor DNA. J Clin Oncol. 2014;32(6):579-586. doi:10.1200/ JCO.2012.45.2011

23. Bettegowda C, Sausen M, Leary RJ, et al. Detection of circulating tumor DNA in early- and late-stage human malignancies. Sci Transl Med. 2014;6(224):224ra24. doi:10.1126/scitranslmed.3007094

24. Garcia-Murillas I, Schiavon G, Weigelt B, et al. Mutation tracking in circulating tumor DNA predicts relapse in early breast cancer. Sci Transl Med. 2015;7(302):302ra133. doi:10.1126/scitranslmed. aab0021

25. Vitale SR, Sieuwerts AM, Beije N, et al. An optimized workflow to evaluate estrogen receptor gene mutations in small amounts of cell-free DNA. J Mol Diagn. 2019;21(1):123-137. doi:10.1016/j. jmoldx.2018.08.010

26. Tzanikou E, Markou A, Politaki E, et al. PIK3CA hotspot mutations in circulating tumor cells and paired circulating tumor DNA in breast cancer: a direct comparison study. Mol Oncol. 2019;13 (12):2515-2530. doi:10.1002/1878-0261.12540

27. Gyanchandani R, Kvam E, Heller R, et al. Whole genome amplification of cell-free DNA enables detection of circulating tumor DNA mutations from fingerstick capillary blood. Sci Rep. 2018;8 (1):17313. doi:10.1038/s41598-018-35470-9

28. Perakis S, Speicher MR. Emerging concepts in liquid biopsies. BMC Med. 2017;15(1):75. doi:10.1186/s12916-017-0840-6

29. Smith NG, Gyanchandani R, Shah OS, et al. Targeted mutation detection in breast cancer using MammaSeq. Breast Cancer Res. 2019;21(1):22. doi:10.1186/s13058-019-1102-7

30. Newman AM, Lovejoy AF, Klass DM, et al. Integrated digital error suppression for improved detection of circulating tumor DNA. Nat Biotechnol. 2016;34(5):547-555. doi:10.1038/nbt.3520

31. Masunaga N, Kagara N, Motooka D, et al. Highly sensitive detection of ESR1 mutations in cell-free DNA from patients with metastatic breast cancer using molecular barcode sequencing. Breast Cancer Res Treat. 2018;167(1):49-58. doi:10.1007/s10549-0174487-y

32. Gerratana L, Zhang Q, Shah AN, et al. Performance of a novel next generation sequencing circulating tumor DNA (ctDNA) platform for the evaluation of samples from patients with metastatic breast cancer (MBC). Crit Rev Oncol Hemat. 2020;145:102856. doi:10.10 16/j.critrevonc.2019.102856

33. Stetson D, Ahmed A, Xu X, et al. Orthogonal comparison of four plasma NGS tests with tumor suggests technical factors are a major source of assay discordance. JCO Precis Oncol. 2019;3:1-9.

34. Keup C, Benyaa K, Hauch S, et al. Targeted deep sequencing revealed variants in cell-free DNA of hormone receptor-positive metastatic breast cancer patients. Cell Mol Life Sci. 2020;77 (3):497-509. doi:10.1007/s00018-019-03189-z

35. Wyatt AW, Annala M, Aggarwal R, et al. Concordance of circulating tumor DNA and matched metastatic tissue biopsy in prostate cancer. J Natl Cancer Inst. 2017;109(12):12. doi:10.1093/jnci/djx 118 
36. Baselga J, Im SA, Iwata $H$, et al. Buparlisib plus fulvestrant versus placebo plus fulvestrant in postmenopausal, hormone receptor-positive, HER2-negative, advanced breast cancer (BELLE-2): a randomised, double-blind, placebo-controlled, phase 3 trial. Lancet Oncol. 2017;18 (7):904-916. doi:10.1016/S1470-2045(17)30376-5

37. Di Leo A, Johnston S, Lee KS, et al. Buparlisib plus fulvestrant in postmenopausal women with hormone-receptor-positive, HER2-negative, advanced breast cancer progressing on or after mTOR inhibition (BELLE-3): a randomised, double-blind, placebo-controlled, phase 3 trial. Lancet Oncol. 2018;19 (1):87-100. doi:10.1016/S1470-2045(17)30688-5

38. Kodahl AR, Ehmsen S, Pallisgaard N, et al. Correlation between circulating cell-free PIK3CA tumor DNA levels and treatment response in patients with PIK3CA-mutated metastatic breast cancer. Mol Oncol. 2018;12(6):925-935. doi:10.1002/1878-0261. 12305

39. Adalsteinsson VA, Ha G, Freeman SS, et al. Scalable whole-exome sequencing of cell-free DNA reveals high concordance with metastatic tumors. Nat Commun. 2017;8(1):1324. doi:10.1038/s41467017-00965-y

40. Chung JH, Pavlick D, Hartmaier R, et al. Hybrid capture-based genomic profiling of circulating tumor DNA from patients with estrogen receptor-positive metastatic breast cancer. Ann Oncol. 2017;28(11):2866-2873. doi:10.1093/annonc/mdx490

41. Crowley E, Di Nicolantonio F, Loupakis F, Bardelli A. Liquid biopsy: monitoring cancer-genetics in the blood. Nat Rev Clin Oncol. 2013;10(8):472-484. doi:10.1038/nrclinonc.2013.110

42. Maxwell KN, Soucier-Ernst D, Tahirovic E, et al. Comparative clinical utility of tumor genomic testing and cell-free DNA in metastatic breast cancer. Breast Cancer Res Treat. 2017;164 (3):627-638. doi:10.1007/s10549-017-4257-x

43. Shatsky R, Parker BA, Bui NQ, et al. Next-generation sequencing of tissue and circulating tumor DNA: the UC San Diego Moores center for personalized cancer therapy experience with breast malignancies. Mol Cancer Ther. 2019;18(5):1001-1011. doi:10.11 58/1535-7163.MCT-17-1038

44. Goetz MP, Suman VJ, Reid JM, et al. First-in-human phase i study of the tamoxifen metabolite Z-Endoxifen in women with endocrine-refractory metastatic breast cancer. $J$ Clin Oncol. 2017;35(30):3391-3400. doi:10.1200/JCO.2017.73.3246

45. Ma F, Li Q, Chen S, et al. Phase I study and biomarker analysis of pyrotinib, a novel irreversible Pan-ErbB receptor tyrosine kinase inhibitor, in patients with human epidermal growth factor receptor 2-positive metastatic breast cancer. J Clin Oncol. 2017;35 (27):3105-3112. doi:10.1200/JCO.2016.69.6179

46. Takeshita T, Yamamoto Y, Yamamoto-Ibusuki $\mathrm{M}$, et al. Comparison of ESR1 mutations in tumor tissue and matched plasma samples from metastatic breast cancer patients. Transl Oncol. 2017;10(5):766-771. doi:10.1016/j.tranon.2017.07.004

47. Gerlinger M, Rowan AJ, Horswell S, et al. Intratumor heterogeneity and branched evolution revealed by multiregion sequencing. $N$ Engl J Med. 2012;366(10):883-892. doi:10.1056/NEJMoa11 13205

48. Savli H, Sertdemir N, Aydin D, et al. TP53, EGFR and PIK3CA gene variations observed as prominent biomarkers in breast and lung cancer by plasma cell-free DNA genomic testing. J Biotechnol. 2019;300:87-93. doi:10.1016/j.jbiotec.2019.05.005

49. Risberg B, Tsui DWY, Biggs H, et al. Effects of collection and processing procedures on plasma circulating cell-free DNA from cancer patients. J Mol Diagn. 2018;20(6):883-892. doi:10.1016/j. jmoldx.2018.07.005

50. Takeshita T, Yamamoto Y, Yamamoto-Ibusuki M, Tomiguchi M, Sueta A, Iwase H. ESR1 and PIK3CA mutational status in serum and plasma from metastatic breast cancer patients: a comparative study. Cancer Biomark. 2018;22(2):345-350. doi:10.3233/CBM171161
51. Ziegler A, Zangemeister-Wittke U, Stahel RA. Circulating DNA: a new diagnostic gold mine? Cancer Treat Rev. 2002;28 (5):255-271. doi:10.1016/S0305-7372(02)00077-4

52. Lam NYL, Rainer TH, Chiu RWK, Lo YM. EDTA is a better anticoagulant than heparin or citrate for delayed blood processing for plasma DNA analysis. Clin Chem. 2004;50(1):256-257. doi:10. 1373/clinchem.2003.026013

53. Seymour L, Bogaerts J, Perrone A, et al. iRECIST: guidelines for response criteria for use in trials testing immunotherapeutics. Lancet Oncol. 2017;18(3):e143-e152. doi:10.1016/S1470-2045(17) 30074-8

54. Ma F, Guan Y, Yi Z, et al. Assessing tumor heterogeneity using ctDNA to predict and monitor therapeutic response in metastatic breast cancer. Int J Cancer. 2020;146(5):1359-1368. doi:10.1002/ ijc. 32536

55. Rossi G, Mu Z, Rademaker AW, et al. Cell-free DNA and circulating tumor cells: comprehensive liquid biopsy analysis in advanced breast cancer. Clin Cancer Res. 2018;24(3):560-568. doi:10.1158/ 1078-0432.CCR-17-2092

56. Cheng J, Holland-Letz $\mathrm{T}$, Wallwiener $\mathrm{M}$, et al. Circulating free DNA integrity and concentration as independent prognostic markers in metastatic breast cancer. Breast Cancer Res Treat. 2018;169 (1):69-82. doi:10.1007/s10549-018-4666-5

57. Cristofanilli M, Budd GT, Ellis MJ, et al. Circulating tumor cells, disease progression, and survival in metastatic breast cancer. N Engl J Med. 2004;351(8):781-791. doi:10.1056/NEJMoa040766

58. Hayes DF, Cristofanilli M, Budd GT, et al. Circulating tumor cells at each follow-up time point during therapy of metastatic breast cancer patients predict progression-free and overall survival. Clin Cancer Res. 2006;12(14 Pt 1):4218-4224. doi:10.1158/1078-0432. CCR-05-2821

59. Cristofanilli M, Pierga JY, Reuben J, et al. The clinical use of circulating tumor cells (CTCs) enumeration for staging of metastatic breast cancer (MBC): international expert consensus paper. Crit Rev Oncol Hemat. 2019;134:39-45. doi:10.1016/j.critrevonc. 2018.12.004

60. Stover DG, Parsons HA, Ha G, et al. Association of cell-free DNA tumor fraction and somatic copy number alterations with survival in metastatic triple-negative breast cancer. J Clin Oncol. 2018;36 (6):543-553. doi:10.1200/JCO.2017.76.0033

61. Jiang WW, Zahurak M, Goldenberg D, et al. Increased plasma DNA integrity index in head and neck cancer patients. Int $J$ Cancer. 2006;119(11):2673-2676. doi:10.1002/ijc.22250

62. Wang BG, Huang HY, Chen YC, et al. Increased plasma DNA integrity in cancer patients. Cancer Res. 2003;63(14):3966-3968.

63. El-Shazly SF, Eid MA, El-Sourogy HA, Attia GF, Ezzat SA. Evaluation of serum DNA integrity as a screening and prognostic tool in patients with hepatitis $\mathrm{C}$ virus-related hepatocellular carcinoma. Int J Biol Markers. 2010;25(2):79-86. doi:10.1177/ 172460081002500204

64. Hussein NA, Mohamed SN, Ahmed MA. Plasma ALU-247, ALU-115, and cfDNA integrity as diagnostic and prognostic biomarkers for breast cancer. Appl Biochem Biotechnol. 2019;187 (3):1028-1045. doi:10.1007/s12010-018-2858-4

65. Takano T, Tsurutani J, Takahashi M, et al. A randomized Phase II trial of trastuzumab plus capecitabine versus lapatinib plus capecitabine in patients with HER2-positive metastatic breast cancer previously treated with trastuzumab and taxanes: WJOG6110B/ ELTOP. Breast. 2018;40:67-75. doi:10.1016/j.breast.2018.04.010

66. Rothe F, Laes JF, Lambrechts D, et al. Plasma circulating tumor DNA as an alternative to metastatic biopsies for mutational analysis in breast cancer. Ann Oncol. 2014;25(10):1959-1965. doi:10.10 93/annonc/mdu288

67. Ding Q, Chen H, Lim B, et al. HER2 somatic mutation analysis in breast cancer: correlation with clinicopathological features. Hum Pathol. 2019;92:32-38. doi:10.1016/j.humpath.2019.07.006 
68. Yi Z, Ma F, Li C, et al. Landscape of somatic mutations in different subtypes of advanced breast cancer with circulating tumor DNA analysis. Sci Rep. 2017;7(1):5995. doi:10.1038/ s41598-017-06327-4

69. Zill OA, Banks KC, Fairclough SR, et al. The landscape of actionable genomic alterations in cell-free circulating tumor DNA from 21,807 advanced cancer patients. Clin Cancer Res. 2018;24 (15):3528-3538. doi:10.1158/1078-0432.CCR-17-3837

70. Yang X, Zhang K, Zhang C, Peng R, Sun C. Accuracy of analysis of cfDNA for detection of single nucleotide variants and copy number variants in breast cancer. BMC Cancer. 2019;19(1):465. doi:10.1186/s12885-019-5698-x

71. Green BB, Karagas MR, Punshon T, et al. Epigenome-wide assessment of DNA methylation in the placenta and arsenic exposure in the new hampshire birth cohort study (USA). Environ Health Perspect. 2016;124(8):1253-1260. doi:10.1289/ehp.1510437

72. Fackler MJ, Lopez BZ, Umbricht C, et al. Novel methylated biomarkers and a robust assay to detect circulating tumor DNA in metastatic breast cancer. Cancer Res. 2014;74(8):2160-2170. doi:10.1158/0008-5472.CAN-13-3392

73. Warton K, Mahon KL, Samimi G. Methylated circulating tumor DNA in blood: power in cancer prognosis and response. Endocr Relat Cancer. 2016;23(3):R157-R171. doi:10.1530/ERC-150369

74. Le AV, Szaumkessel M, Tan TZ, Thiery JP, Thompson EW, Dobrovic A. DNA methylation profiling of breast cancer cell lines along the epithelial mesenchymal spectrum-implications for the choice of circulating tumour DNA methylation markers. Int J Mol Sci. 2018;19(9). doi:10.3390/ijms19092553

75. Jackson JR, Kim Y, Seeger RC, Kim ES. A novel minimal residual disease model of neuroblastoma in mice. J Pediatr Surg. 2016;51 (6):991-994. doi:10.1016/j.jpedsurg.2016.02.066

76. Panagopoulou M, Karaglani M, Balgkouranidou I, et al. Circulating cell-free DNA in breast cancer: size profiling, levels, and methylation patterns lead to prognostic and predictive classifiers. Oncogene. 2019;38(18):3387-3401. doi:10.1038/s41388-018-06 $60-\mathrm{y}$

77. Gradishar WJ, Anderson BO, Balassanian R, et al. Breast cancer, version 4.2017, NCCN clinical practice guidelines in oncology. J Natl Compr Canc Netw. 2016;13(12):310-320. doi:10.6004/ jncen.2018.0012

78. Alimirzaie S, Bagherzadeh M, Akbari MR. Liquid biopsy in breast cancer: a comprehensive review. Clin Genet. 2019;95(6):643-660. doi:10.1111/cge. 13514

79. Kalinsky K, Jacks LM, Heguy A, et al. PIK3CA mutation associates with improved outcome in breast cancer. Clin Cancer Res. 2009;15(16):5049-5059. doi:10.1158/1078-0432.CCR-09-0632

80. Karakas B, Bachman KE, Park BH. Mutation of the PIK3CA oncogene in human cancers. Br J Cancer. 2006;94(4):455-459.

81. Park IH, Kong SY, Kwon Y, et al. Phase I/II clinical trial of everolimus combined with gemcitabine/cisplatin for metastatic triple-negative breast cancer. $J$ Cancer. 2018;9(7):1145-1151. doi: $10.7150 /$ jca. 24035

82. O'Leary B, Hrebien S, Morden JP, et al. Early circulating tumor DNA dynamics and clonal selection with palbociclib and fulvestrant for breast cancer. Nat Commun. 2018;9(1):896. doi:10.1038/ s41467-018-03215-x

83. Jacot W, Dalenc F, Lopez-Crapez E, et al. PIK3CA mutations early persistence in cell-free tumor DNA as a negative prognostic factor in metastatic breast cancer patients treated with hormonal therapy. Breast Cancer Res Treat. 2019;177(3):659-667. doi:10.1007/ s10549-019-05349-y

84. Li H, Xu Y, Zhao F, et al. Plasma PIK3CA ctDNA specific mutation detected by next generation sequencing is associated with clinical outcome in advanced breast cancer. Am J Cancer Res. 2018;8(9):1873-1886.
85. Early Breast Cancer Trialists' Collaborative Group (EBCTCG). Effects of chemotherapy and hormonal therapy for early breast cancer on recurrence and 15-year survival: an overview of the randomised trials. Lancet. 2005;365(9472):1687-1717. doi:10.10 16/S0140-6736(05)66544-0

86. Allouchery V, Beaussire L, Perdrix A, et al. Circulating ESR1 mutations at the end of aromatase inhibitor adjuvant treatment and after relapse in breast cancer patients. Breast Cancer Res. 2018;20(1):40. doi:10.1186/s13058-018-0968-0

87. Chandarlapaty S, Chen D, He W, et al. Prevalence of ESR1 mutations in cell-free DNA and outcomes in metastatic breast cancer: a secondary analysis of the BOLERO-2 clinical trial. JAMA Oncol. 2016;2(10):1310-1315. doi:10.1001/jamaoncol.2016.1279

88. Paoletti C, Schiavon G, Dolce EM, et al. Circulating biomarkers and resistance to endocrine therapy in metastatic breast cancers: correlative results from AZD9496 oral SERD Phase I trial. Clin Cancer Res. 2018;24(23):5860-5872. doi:10.1158/1078-0432.CCR-18-1569

89. Pritchard KI. Endocrine therapy: is the first generation of targeted drugs the last? J Intern Med. 2013;274(2):144-152. doi:10.1111/ joim. 12065

90. Fribbens C, O'Leary B, Kilburn L, et al. Plasma ESR1 mutations and the treatment of estrogen receptor-positive advanced breast cancer. J Clin Oncol. 2016;34(25):2961-2968. doi:10.1200/JCO.2016.67.3061

91. Clatot F, Perdrix A, Augusto L, et al. Kinetics, prognostic and predictive values of ESR1 circulating mutations in metastatic breast cancer patients progressing on aromatase inhibitor. Oncotarget. 2016;7(46):74448-74459. doi:10.18632/oncotarget.12950

92. Schiavon G, Hrebien S, Garcia-Murillas I, et al. Analysis of ESR1 mutation in circulating tumor DNA demonstrates evolution during therapy for metastatic breast cancer. Sci Transl Med. 2015;7 (313):313ra182. doi:10.1126/scitranslmed.aac7551

93. Beije N, Sieuwerts AM, Kraan J, et al. Estrogen receptor mutations and splice variants determined in liquid biopsies from metastatic breast cancer patients. Mol Oncol. 2018;12(1):48-57. doi:10.1002/ 1878-0261.12147

94. Takeshita T, Yamamoto Y, Yamamoto-Ibusuki M, et al. Prevalence of ESR1 E380Q mutation in tumor tissue and plasma from Japanese breast cancer patients. BMC Cancer. 2017;17(1):786. doi:10.1186/s12885-017-3779-2

95. Ma CX, Bose R, Gao F, et al. Neratinib efficacy and circulating tumor DNA detection of HER2 mutations in HER2 nonamplified metastatic breast cancer. Clin Cancer Res. 2017;23(19):5687-5695. doi:10.1158/1078-0432.CCR-17-0900

96. Condorelli R, Spring L, O’Shaughnessy J, et al. Polyclonal RB1 mutations and acquired resistance to CDK 4/6 inhibitors in patients with metastatic breast cancer. Ann Oncol. 2018;29(3):640-645. doi:10.1093/annonc/mdx784

97. Lok SW, Whittle JR, Vaillant F, et al. A Phase Ib dose-escalation and expansion study of the BCL2 inhibitor venetoclax combined with tamoxifen in ER and BCL2-positive metastatic breast cancer. Cancer Discov. 2019;9(3):354-369. doi:10.1158/2159-8290.CD-18-1151

98. Slamon DJ, Godolphin W, Jones LA, et al. Studies of the HER-2/ neu proto-oncogene in human breast and ovarian cancer. Science. 1989;244(4905):707-712. doi:10.1126/science.2470152

99. Burstein HJ. The distinctive nature of HER2-positive breast cancers. $N$ Engl J Med. 2005;353(16):1652-1654. doi:10.1056/ NEJMp058197

100. Abramson V, Arteaga CL. New strategies in HER2-overexpressing breast cancer: many combinations of targeted drugs available. Clin Cancer Res. 2011;17(5):952-958. doi:10.1158/1078-0432.CCR-091947

101. Sakai H, Tsurutani J, Iwasa T, et al. HER2 genomic amplification in circulating tumor DNA and estrogen receptor positivity predict primary resistance to trastuzumab emtansine (T-DM1) in patients with HER2-positive metastatic breast cancer. Breast Cancer. 2018;25(5):605-613. doi:10.1007/s12282-018-0861-9 
102. Li Q, Guan X, Chen S, et al. Safety, efficacy, and biomarker analysis of pyrotinib in combination with capecitabine in HER2-positive metastatic breast cancer patients: a Phase I clinical trial. Clin Cancer Res. 2019;25(17):5212-5220. doi:10.1158/10780432.CCR-18-4173

103. Vogel CL, Cobleigh MA, Tripathy D, et al. Efficacy and safety of trastuzumab as a single agent in first-line treatment of HER2-overexpressing metastatic breast cancer. $J$ Clin Oncol. 2002;20(3):719-726. doi:10.1200/JCO.2002.20.3.719

104. Bose R, Kavuri SM, Searleman AC, et al. Activating HER2 mutations in HER2 gene amplification negative breast cancer. Cancer Discov. 2013;3(2):224-237. doi:10.1158/2159-8290.CD-12-0349

105. Grellety T, Soubeyran I, Robert J, Bonnefoi H, Italiano A. A clinical case of invasive lobular breast carcinoma with ERBB2 and CDH1 mutations presenting a dramatic response to anti-HER2directed therapy. Ann Oncol. 2016;27(1):199-200. doi:10.1093/ annonc/mdv496

106. Ross JS, Gay LM, Nozad S, et al. Clinically advanced and metastatic pure mucinous carcinoma of the breast: a comprehensive genomic profiling study. Breast Cancer Res Treat. 2016;155 (2):405-413. doi:10.1007/s10549-016-3682-6

107. Murphree AL, Benedict WF. Retinoblastoma: clues to human oncogenesis. Science. 1984;223(4640):1028-1033. doi:10.1126/ science.6320372

108. Cancer Genome Atlas Network. Comprehensive molecular portraits of human breast tumours. Nature. 2012;490(7418):61-70. doi:10.1038/nature11412

109. Perillo B, Sasso A, Abbondanza C, Palumbo G. 17beta-estradiol inhibits apoptosis in MCF-7 cells, inducing bcl-2 expression via two estrogen-responsive elements present in the coding sequence. Mol Cell Biol. 2000;20(8):2890-2901. doi:10.1128/MCB.20.8.28 90-2901.2000

110. Vaillant F, Merino D, Lee L, et al. Targeting BCL-2 with the BH3 mimetic ABT-199 in estrogen receptor-positive breast cancer. Cancer Cell. 2013;24(1):120-129. doi:10.1016/j.ccr.2013.06.002

111. Mastoraki S, Strati A, Tzanikou E, et al. ESR1 methylation: a liquid biopsy-based epigenetic assay for the follow-up of patients with metastatic breast cancer receiving endocrine treatment. Clin Cancer Res. 2018;24(6):1500-1510. doi:10.1158/1078-0432.CCR17-1181
112. Jeselsohn R, Buchwalter G, De Angelis C, Brown M, Schiff R. ESR1 mutations-a mechanism for acquired endocrine resistance in breast cancer. Nat Rev Clin Oncol. 2015;12(10):573-583. doi:10. 1038/nrclinonc. 2015.117

113. Kuang Y, Siddiqui B, Hu J, et al. Unraveling the clinicopathological features driving the emergence of ESR1 mutations in metastatic breast cancer. NPJ Breast Cancer. 2018;4:22. doi:10.1038/s41523018-0075-5

114. Ribas R, Pancholi S, Rani A, et al. Targeting tumour re-wiring by triple blockade of mTORC1, epidermal growth factor, and oestrogen receptor signalling pathways in endocrine-resistant breast cancer. Breast Cancer Res. 2018;20(1):44. doi:10.1186/s13058018-0983-1

115. Zhou D, Ouyang Q, Liu L, et al. Chemotherapy modulates endocrine therapy-related resistance mutations in metastatic breast cancer. Transl Oncol. 2019;12(5):764-774. doi:10.1016/j.tranon.20 19.02.014

116. Turner NC, Neven P, Loibl S, Andre F. Advances in the treatment of advanced oestrogen-receptor-positive breast cancer. Lancet. 2017;389(10087):2403-2414. doi:10.1016/S0140-6736(16)32419-9

117. Pernas S, Tolaney SM, Winer EP, Goel S. CDK4/6 inhibition in breast cancer: current practice and future directions. Ther Adv Med Oncol. 2018;10:1758835918786451. doi:10.1177/1758835918786451

118. Finn RS, Dering J, Conklin D, et al. PD 0332991, a selective cyclin D kinase 4/6 inhibitor, preferentially inhibits proliferation of luminal estrogen receptor-positive human breast cancer cell lines in vitro. Breast Cancer Res. 2009;11(5):R77. doi:10.1186/bcr2419

119. Malorni L, Curigliano G, Minisini AM, et al. Palbociclib as single agent or in combination with the endocrine therapy received before disease progression for estrogen receptor-positive, HER2-negative metastatic breast cancer: tREnd trial. Ann Oncol. 2018;29 (8):1748-1754. doi:10.1093/annonc/mdy214

120. O'Leary B, Cutts RJ, Liu Y, et al. The genetic landscape and clonal evolution of breast cancer resistance to palbociclib plus fulvestrant in the PALOMA-3 trial. Cancer Discov. 2018;8(11):1390-1403. doi:10.1158/2159-8290.CD-18-0264

121. Formisano L, Lu Y, Servetto A, et al. Aberrant FGFR signaling mediates resistance to CDK4/6 inhibitors in ER+ breast cancer. Nat Commun. 2019;10(1):1373. doi:10.1038/s41467-019-09068-2

\section{Publish your work in this journal}

Cancer Management and Research is an international, peer-reviewed open access journal focusing on cancer research and the optimal use of preventative and integrated treatment interventions to achieve improved outcomes, enhanced survival and quality of life for the cancer patient.
The manuscript management system is completely online and includes a very quick and fair peer-review system, which is all easy to use. Visit http://www.dovepress.com/testimonials.php to read real quotes from published authors. 